\title{
Coverage of genetic therapies for spinal muscular atrophy across fee-for-service Medicaid programs
}

\begin{abstract}
Jeromie Ballreich, PhD, MHS; Ijeamaka Ezebilo, MD, MPH; Banda Abdallah Khalifa, MD, MPH, MBA; Joshua Choe, BA; and Gerard Anderson, PhD
\end{abstract}

\section{What is already known about this subject}

- Genetic therapies offer a tremendous promise for treating many debilitating conditions, but they come at a high price.

- Medicaid programs have limited budgets and may use utilization controls to restrict access to high-priced genetic therapies.

\section{What this study adds}

- This study documents variations in coverage for 2 high-priced genetic therapies across state fee-for-service Medicaid programs.

- Analysis suggests that significant variation exists and that more restrictive states had lower use of nusinersen.

\section{Author affiliations \\ Jeromie Ballreich, PhD, MHS; ljeamaka Ezebilo, MD, MPH; Banda Abdallah Khalifa, MD, MPH, MBA; Joshua Choe, BA; and Gerard Anderson, PhD, Department of Health Policy \& Management and Johns Hopkins Drug Access and Affordability Initiative, Johns Hopkins Bloomberg School of Public Health, Baltimore, MD.}

AUTHOR CORRESPONDENCE: Jeromie Ballreich, 814.599.6001; jballre2@jhu.edu

\author{
J Manag Care Spec Pharm. \\ 2022;28(1):39-47 \\ Copyright $\odot 2022$, Academy of Managed \\ Care Pharmacy. All rights reserved.
}

\section{ABSTRACT}

BACKGROUND: Genetic therapies are a promising treatment for children born with spinal muscular atrophy (SMA); however, their high price tags can evoke coverage restrictions.

OBJECTIVE: To assess variation in coverage guidelines across fee-for-service state Medicaid programs for 2 novel genetic therapies, nusinersen and onasemnogene abeparvovec, that treat SMA. We also assessed the association of these coverage guidelines with use of the 2 genetic therapies.
METHODS: We evaluated fee-for-service Medicaid coverage policies for nusinersen and onasemnogene abeparvovec from publicly available websites for the period February 2020-March 2020. We then documented areas of agreement and disagreement across 4 key coverage domains. We used 2018 and 2019 state Medicaid drug utilization data to calculate the use of nusinersen across Medicaid programs and assessed that use against the restrictiveness of the coverage guidelines.

RESULTS: We identified 19 state Medicaid coverage guidelines for nusinersen. Most states agreed on diagnostics requirements; however, there were disagreements based on ventilator status. We identified 17 state
Medicaid coverage guidelines for onasemnogene abeparvovec. There was more discordance in these coverage guidelines compared with nusinersen, notably in domains of SMN2 gene count and ventilator status. When comparing utilization of nusinersen with coverage restrictions, we found that the more restrictive states had considerably lower utilization of nusinersen.

CONCLUSIONS: There was significant variation across fee-for-service Medicaid coverage policies for nusinersen and onasemnogene abeparvovec. Although states can impose individual coverage guidelines for each drug, we presented policy options that could reduce variation and potentially decrease the cost burden of these drugs. 
Spinal muscular atrophy (SMA) is a genetic disorder that causes a deficiency in the motor neuron protein known as the survival motor neuron (SMN). This deficiency results in a loss of motor neurons, atrophy of the skeletal muscles, and, if left untreated, can lead to progressive loss of motor function and mortality. ${ }^{1}$ Estimates of SMA incidence in the United States range from 1 in 6,000 live births to 1 in 11,000 live births. ${ }^{2}$ Advances in genetic therapies have led to the development of 2 genetic therapies to treat SMA: nusinersen (Spinraza) and onasemnogene abeparvovec (Zolgensma).

These genetic therapies offer children with SMA meaningful clinical benefit with a favorable safety profile. ${ }^{3}$ It has been suggested that early access to treatment can significantly improve a child's outcomes. ${ }^{4}$ While these drugs offer children with SMA a promising treatment option, they do, however, come with a very high price tag. The list price for nusinersen is $\$ 750,000$ in the first year and $\$ 375,000$ for the follow-up doses, which are required each subsequent year throughout the patient's life. ${ }^{5}$ Onasemnogene abeparvovec has a list price of $\$ 2.1$ million, but it is administered as a 1-time therapy. ${ }^{6}$

These high prices are particularly burdensome for state Medicaid programs. Although Medicaid programs receive mandated and supplemental rebates from drug companies, which lower the cost of drugs, they still remain very expensive for the Medicaid programs. We estimated that nusinersen and onasemnogene abeparvovec combined cost state Medicaid programs approximately $\$ 200$ million in 2019, making them the 2 most costly genetic therapies in the Medicaid program.

The budgetary impact of genetic therapies for Medicaid programs is likely to be more problematic than other payers for 3 key reasons. First, Medicaid is the primary payer for approximately 2 out of 5 births in the United States, and it is anticipated that many genetic therapies will be administered to infants with identified disorders. Second, unlike private insurance plans, Medicaid programs cannot have formularies that explicitly restrict drug access, so the stipulations of the Medicaid drug rebate program means that Medicaid programs must cover practically all medically necessary drugs approved by the US Food and Drug Administration. ${ }^{8}$ Third, Medicaid recipients pay very little in copays and coinsurance for drugs, so the Medicaid program bears nearly the entire drug cost and negates the use of cost sharing as a counter to the moral hazard dilemma underpinning insurance design. So, in order to balance their budgets, Medicaid programs have implemented utilization controls, which include coverage guidelines for many high-priced drugs.
In this study, we examined Medicaid coverage guidelines for nusinersen and onasemnogene abeparvovec as examples of how states can control access to high-priced genetic therapies. We first identified state Medicaid programs that have published nusinersen and onasemnogene abeparvovec coverage guidelines on their websites. We then evaluated key attributes of these coverage guidelines and analyzed where guidelines agreed and disagreed on coverage attributes. We also assessed the effect of the restrictiveness of coverage guidelines and their association with the use of these high-priced genetic therapies in state Medicaid programs. In the Discussion section, we contextualize our results and discuss policies to promote access to these and future genetic therapies.

\section{Methods}

We evaluated Medicaid coverage policies for nusinersen and onasemnogene abeparvovec and documented areas of agreement and disagreement for coverage. We then calculated the utilization of these 2 drugs across Medicaid programs, and the effect of guidelines on their utilization.

\section{MEDICAID COVERAGE GUIDELINES}

We identified state-specific Medicaid coverage guidelines for nusinersen and onasemnogene abeparvovec using targeted web searches. Two researchers (IE and BK) independently searched state Medicaid websites for coverage guidelines from February 1, 2020, through March 16, 2020. We focused on fee-for-service (FFS) Medicaid state websites rather than those for third-party managed care organizations (MCOs). This choice was motivated by our belief that it would be easier for state Medicaid directors to implement policy change for select drugs in the FFS domain compared with implementing a policy change in the MCO domain, which typically involves established contracts that manage the MCO.

Once a coverage policy was identified, it was independently documented using an agreed-upon protocol (see Supplementary Material, available in online article). The documentation process included categorizing key coverage attributes and recording them in a master file. The 2 independently created master files with coverage attributes were then compared, and differences were resolved by a third researcher (JB), using a consensus-driven adjudication process. Comparison of coverage guidelines between the 2 genetic therapies were statistically analyzed using chi-square tests. 


\section{TABLE 1}

States with Medicaid Coverage Policies and Their Characteristics

\begin{tabular}{|c|c|c|c|}
\hline & $\begin{array}{l}\text { Total FFS } \\
\text { Medicaid } \\
\text { births, }{ }^{\text {a }} \mathbf{n}\end{array}$ & $\begin{array}{c}\text { Average } \\
\text { Medicaid } \\
\text { spending per } \\
\text { child, \$ }\end{array}$ & $\begin{array}{c}\text { ACA } \\
\text { expansion }\end{array}$ \\
\hline Out-of-sample states & 87,533 & 3,626 & $\begin{array}{c}70.8 \% \\
(17 / 24) \\
\end{array}$ \\
\hline Nusinersen & 166,160 & 3,445 & $\begin{array}{c}73.6 \% \\
(14 / 19)\end{array}$ \\
\hline Onasemnogene abeparvovec & 156,266 & 3,868 & $\begin{array}{c}82.4 \% \\
(14 / 17)\end{array}$ \\
\hline \multicolumn{4}{|l|}{ Individual states } \\
\hline \multicolumn{4}{|l|}{ Both drugs } \\
\hline Colorado & 952 & 2,982 & Yes \\
\hline Connecticut & 12,918 & 3,715 & Yes \\
\hline Florida & 22,472 & 2,072 & No \\
\hline lowa & 930 & 3,060 & Yes \\
\hline Louisiana & 6,111 & 3,531 & Yes \\
\hline Maryland & 5,672 & 3,699 & Yes \\
\hline Texas & 30,589 & 3,885 & No \\
\hline Utah & 220 & 4,151 & Yes \\
\hline Wisconsin & 7,951 & 2,792 & No \\
\hline
\end{tabular}

Nusinersen only

\begin{tabular}{l|r|r|l}
\hline California & 48,870 & 2,789 & Yes \\
\hline Illinois & 6,228 & 2,532 & Yes \\
\hline Maine & 771 & 4,505 & Yes \\
\hline Mississippi & 7,248 & 4,053 & No \\
\hline Montana & 1,240 & 4,380 & Yes \\
\hline Nebraska & 385 & 5,580 & Yes \\
\hline Nevada & 2,023 & 2,882 & Yes \\
\hline South Dakota & 880 & 3,256 & No \\
\hline Washington & 33,487 & 2,724 & Yes \\
\hline West Virginia & 5,342 & 2,869 & Yes \\
\hline Onasemnogene abeparvovec only & & & \\
\hline Indiana & 8,962 & 4,096 & Yes \\
\hline Minnesota & 5,672 & 3,172 & Yes \\
\hline Missouri & 664 & 4,248 & Yes \\
\hline New York & 26,116 & 3,838 & Yes \\
\hline North Dakota & 1,157 & 6,847 & Yes \\
\hline Ohio & 13,907 & 3,510 & Yes \\
\hline Oklahoma & 8,669 & 3,934 & Yes \\
\hline Oregon & 3,304 & 6,604 & Yes \\
\hline
\end{tabular}

aTotal FFS Medicaid births were calculated using proportion of state enrollees in FFS Medicaid multiplied by total estimated Medicaid births.

$A C A=$ Affordable Care Act; FFS= fee for service .

\section{STATE MEDICAID CHARACTERISTICS}

Additional information on state Medicaid programs was collected from restricted-access and publicly available data as follows. State Medicaid drug utilization for nusinersen and onasemnogene abeparvovec was estimated using the branded drug names in restricted-access state Medicaid drug utilization files. ${ }^{9}$ State Medicaid births were estimated using the Centers for Disease Control and Prevention's (CDC) National Vital Statistics System and March of Dimes data. ${ }^{10,11}$ The CDC data provided total births by state, and the March of Dimes provided the proportion of births for whom Medicaid was the primary payer. We then estimated the proportion of these births to be allocated to FFS Medicaid based on the proportion of FFS Medicaid enrollees compared with total Medicaid beneficiaries in each state. ${ }^{12}$ These population statistics yielded estimates of total FFS Medicaid births. We then estimated nusinersen utilization per 10,000 Medicaid FFS births using the Medicaid drug utilization data. We concluded that utilization estimates were premature for onasemnogene abeparvovec, given that it was approved in May 2019,13 which left only 7 months of observable utilization data in our dataset.

We also compared our sample state Medicaid characteristics with out-of-sample state Medicaid characteristics using 2 metrics: (1) whether a state expanded Medicaid and (2) per child Medicaid spending. ${ }^{14,15}$ We used a Fisher exact test to compare Medicaid expansion in our sample with out-of-sample states, and a Wilcoxon rank sum test to compare sample with out-of-sample per child state Medicaid spending.

\section{MEDICAID RESTRICTION SCORE}

We developed a Medicaid restriction score based on 4 coverage guideline components: SMN2 count required, restriction based on ventilator status, baseline motor function required, and whether a specialist was required. These 4 components were selected based on a review of nusinersen and the key clinical considerations for nusinersen utilization. ${ }^{16}$ For each of these components, we assigned a binary value based on whether the state Medicaid guideline for that component was restrictive or unrestrictive. Restrictive components were assigned values of one, and unrestrictive components were assigned values of zero. These values were aggregated for each state to create a state's Medicaid restriction score. We then compared restriction scores to nusinersen utilization per 10,000 Medicaid FFS births. 


\section{TABLE 2 Medicaid Coverage Policies for Nusinersen}

\begin{tabular}{|c|c|c|}
\hline Policy & $\begin{array}{l}\text { Frequency, } n(\%) \\
\qquad(\mathrm{N}=19)\end{array}$ & States \\
\hline \multicolumn{3}{|l|}{ Prior authorization } \\
\hline Required & $18 \quad(94.7)$ & $\begin{array}{l}\text { California, Colorado, Connecticut, Florida, Illinois, lowa, Louisiana, Maine, } \\
\text { Mississippi, Montana, Nebraska, Nevada, South Dakota, Texas, Utah, } \\
\text { Washington, West Virginia, Wisconsin }\end{array}$ \\
\hline Not expressly required & $1 \quad(5.3)$ & Maryland \\
\hline \multicolumn{3}{|l|}{ Genetic characteristics } \\
\hline Genetic SMA diagnosis required & $18 \quad(94.7)$ & $\begin{array}{l}\text { California, Colorado, Connecticut, Florida, Illinois, Iowa, Louisiana, Maine, } \\
\text { Maryland, Montana, Nebraska, Nevada, South Dakota, Texas, Utah, } \\
\text { Washington, West Virginia, Wisconsin }\end{array}$ \\
\hline SMN2 count required & $14 \quad(73.7)$ & $\begin{array}{l}\text { California, Colorado, Connecticut, Florida, Illinois, Louisiana, Maine, } \\
\text { Maryland, Montana, Nebraska, South Dakota, Utah, Washington, Wisconsin }\end{array}$ \\
\hline \multicolumn{3}{|l|}{ Patient characteristics } \\
\hline Restricted by patient age & $2(10.5)$ & Illinois, Texas \\
\hline Eligibility based on symptom onset & $0 \quad(0.0)$ & \\
\hline Restricted by ventilatory status & $8 \quad(42.1)$ & $\begin{array}{l}\text { Colorado, Connecticut, Florida, Illinois, Maine, Maryland, South Dakota, } \\
\text { Utah }\end{array}$ \\
\hline Baseline motor function required & $17 \quad(89.5)$ & $\begin{array}{l}\text { California, Colorado, Connecticut, Florida, Illinois, lowa, Louisiana, Maine, } \\
\text { Montana, Nebraska, South Dakota, Texas, Utah, Washington, West Virginia, } \\
\text { Wisconsin, Nevada }\end{array}$ \\
\hline \multicolumn{3}{|l|}{ Provider characteristic } \\
\hline Unspecified & $3(15.8)$ & lowa, Utah, Washington \\
\hline Specialist (eg, pediatrician, neurologist) & $10 \quad(52.6)$ & $\begin{array}{l}\text { California, Connecticut, Florida, Maine, Maryland, Nebraska, Nevada, South } \\
\text { Dakota, Texas, West Virginia }\end{array}$ \\
\hline $\begin{array}{l}\text { Subspecialist (eg, pediatric neurologist, } \\
\text { pediatric neuromuscular specialist) }\end{array}$ & $4 \quad(21.1)$ & California, Florida, Illinois, Louisiana \\
\hline \multicolumn{3}{|l|}{ Previous treatment } \\
\hline No previous treatment with nusinersen & $0 \quad(0.0)$ & \\
\hline $\begin{array}{l}\text { No previous treatment with } \\
\text { onasemnogene abeparvovec }\end{array}$ & $1 \quad(5.3)$ & Wisconsin \\
\hline $\begin{array}{l}\text { No concurrent onasemnogene } \\
\text { abeparvovec treatment }\end{array}$ & $1 \quad(5.3)$ & Utah \\
\hline
\end{tabular}

\section{Results}

\section{NUSINERSEN COVERAGE GUIDELINES}

We identified 19 states with FFS Medicaid that had their coverage guidelines for nusinersen on their websites, along with their corresponding Medicaid characteristics (Table 1). These states represented approximately 166,000 Medicaid births in 2018, with an average per child Medicaid spending of $\$ 3,445$. States with identified guidelines were spread out geographically and represented many of the more populous states. States in our nusinersen sample were not more likely to be a Medicaid expansion state $(73.6 \%$ of states in our sample expanded Medicaid vs $70.8 \%$ of the out-of-sample states $[P=0.52])$ nor did they have significantly different Medicaid spending per child $(\$ 3,445$ Medicaid spending per child for states in our sample vs $\$ 3,626$ Medicaid spending per child for the out-of-sample states [P=0.32]).

The majority (95\%) of the 19 states required prior authorization and had detailed prior authorization requirements (Table 2). There was more variation in the coverage policies involving genetic characteristics. Nearly all (95\%) states required a formal SMA diagnosis; however, only 14 (74\%) of the 19 states required an SMN2 gene count. Of those 14 states, all but Colorado restricted coverage based 


\section{TABLE 3 Medicaid Coverage Policies for Onasemnogene Abeparvovec}

\begin{tabular}{|c|c|c|}
\hline Policy & $\begin{array}{l}\text { Frequency, } n(\%) \\
\qquad(\mathrm{N}=17)\end{array}$ & States \\
\hline \multicolumn{3}{|l|}{ Prior authorization } \\
\hline Required & $15(88.2)$ & $\begin{array}{l}\text { Connecticut, Florida, Indiana, lowa, Louisiana, Maryland, Minnesota, } \\
\text { Missouri, North Dakota, Ohio Oklahoma, Oregon, Texas, Utah, Wisconsin }\end{array}$ \\
\hline Not expressly required & $2(11.8)$ & Colorado, New York \\
\hline \multicolumn{3}{|l|}{ Genetic characteristics } \\
\hline Genetic SMA diagnosis required & $16(94.1)$ & $\begin{array}{l}\text { Colorado, Connecticut, Florida, Indiana, lowa, Louisiana, Maryland, } \\
\text { Minnesota, Missouri, New York, North Dakota, Oklahoma, Oregon, Texas, } \\
\text { Utah, Wisconsin }\end{array}$ \\
\hline SMN2 count required & $11(64.7)$ & $\begin{array}{l}\text { Colorado, Indiana, lowa, Marylandm, Minnesota, New York, North Dakota, } \\
\text { Oregon, Texas, Utah, Wisconsin }\end{array}$ \\
\hline $\begin{array}{l}\text { Restrictions based on maximum } \\
\text { SMN2 count }\end{array}$ & $11(64.7)$ & $\begin{array}{l}\text { Colorado, Indiana, lowa, Maryland, Minnesota, New York, North Dakota, } \\
\text { Oregon, Texas, Utah, Wisconsin }\end{array}$ \\
\hline \multicolumn{3}{|l|}{ Patient characteristics } \\
\hline Restricted by patient age & $16(94.1)$ & $\begin{array}{l}\text { Colorado, Connecticut, Florida, Indiana, lowa, Louisiana, Maryland, } \\
\text { Minnesota, Missouri, New York, North Dakota, Oklahoma, Oregon, Texas, } \\
\text { Utah, Wisconsin }\end{array}$ \\
\hline Eligibility based on symptom onset & $5(29.4)$ & Colorado, Maryland, Minnesota, North Dakota, Texas \\
\hline Restricted by ventilatory status & $13(76.5)$ & $\begin{array}{l}\text { Colorado, Florida, Indiana, lowa, Louisiana, Maryland, Minnesota, New York, } \\
\text { North Dakota, Oklahoma, Oregon, Utah, Wisconsin }\end{array}$ \\
\hline Baseline motor function required & $7(41.2)$ & Colorado, Florida, Minnesota, North Dakota, Oregon, Texas, Utah \\
\hline \multicolumn{3}{|l|}{ Provider characteristic } \\
\hline Unspecified & $3(17.6)$ & Missouri, New York, Utah \\
\hline Specialist (pediatrician, neurologist, etc.) & $8(47.1)$ & $\begin{array}{l}\text { Colorado, Connecticut, Florida, Iowa, Louisiana, Maryland, North Dakota, } \\
\text { Wisconsin }\end{array}$ \\
\hline $\begin{array}{l}\text { Subspecialist (pediatric neurologist, } \\
\text { pediatric neuromuscular specialist, etc.) }\end{array}$ & $5(29.4)$ & Florida, Minnesota, North Dakota, Oregon, Texas \\
\hline \multicolumn{3}{|l|}{ Previous treatment } \\
\hline No previous treatment with nusinersen & $4(23.5)$ & Colorado, Minnesota, North Dakota, Wisconsin \\
\hline $\begin{array}{l}\text { No previous treatment with onasemnogene } \\
\text { abeparvovec }\end{array}$ & $12(70.6)$ & $\begin{array}{l}\text { Connecticut, Indiana, lowa, Louisiana, Maryland, Minnesota, Missouri, North } \\
\text { Dakota, Oklahoma, Oregon, Texas, Wisconsin }\end{array}$ \\
\hline No concurrent nusinersen treatment & $8(47.1)$ & Iowa, Maryland, Minnesota, Missouri, Oklahoma, Oregon, Texas, Wisconsin \\
\hline
\end{tabular}

on the SMN2 count. Two states restricted access based on a patient's age. Eight states (42\%) restricted access based on ventilator status. Seventeen states (90\%) had a baseline motor function requirement. Ten (53\%) states specified that a child must see a specialist, and 4 (21\%) states required a child to see a subspecialist, such as a pediatric neurologist, before gaining access to nusinersen. One state, Wisconsin, deemed eligibility only if a child had no previous treatment using onasemnogene abeparvovec. In a similar vein, the state of Utah deemed that a child was not eligible for nusinersen if the child was receiving concurrent onasemnogene abeparvovec treatment.

\section{ONASEMNOGENE ABEPARVOVEC COVERAGE GUIDELINES}

We identified 17 states with Medicaid coverage guidelines for onasemnogene abeparvovec on their websites in 2020, along with their corresponding Medicaid characteristics (Table 3). These states represented approximately 156,000 Medicaid births in 2018 with an average per child Medicaid spending of $\$ 3,868$. States in the onasemnogene abeparvovec sample were not more likely to be a Medicaid expansion state $(82.4 \%$ of states in our sample expanded Medicaid vs $70.8 \%$ of the out-of-sample states $[\mathrm{P}=0.41]$ ) nor did they have significantly different Medicaid spending per child (\$3,868 Medicaid spending per child for states in our 


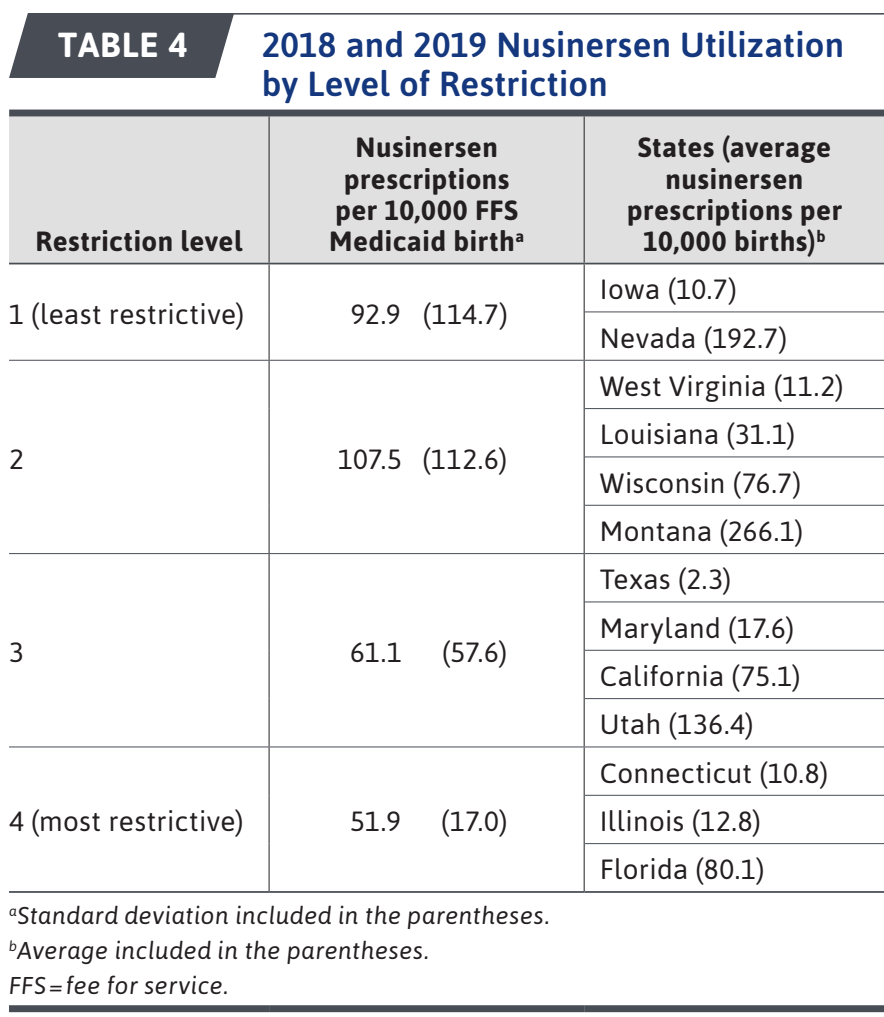

sample vs $\$ 3,626$ Medicaid spending per child for the outof-sample states $[\mathrm{P}=0.22]$ ).

Of the 17 states with coverage guidelines for onasemnogene abeparvovec, 15 required prior authorization. Nearly all (94\%) states required a genetic SMA diagnosis. Eleven (65\%) states required SMN2 counts for onasemnogene abeparvovec. Thirteen (77\%) states limited access to onasemnogene abeparvovec based on ventilator status. Five (29\%) states restricted access to onasemnogene abeparvovec. Approximately half the states required a specialist consultation, and 5 (29\%) required a subspecialist. Four (24\%) states expressly stated no previous treatment with nusinersen, and 8 (47\%) states did not permit concurrent nusinersen treatment. Twelve (71\%) states stated specifically no previous treatment with onasemnogene abeparvovec.

\section{COMPARISON OF NUSINERSEN AND ONASEMNOGENE ABEPARVOVEC COVERAGE GUIDELINES}

States had similar coverage policies for onasemnogene abeparvovec and nusinersen. However, there were some differences. States were more likely to restrict onasemnogene abeparvovec (77\%) based on ventilator status compared with nusinersen (42\%); this difference was statistically significant $(P=0.049)$. States were more likely to restrict onasemnogene abeparvovec (29\%) based on symptom onset, which was not a coverage guideline for nusinersen. Coverage policies around previoius treatment of either drug were much less restrictive for nusinersen compared with onasemnogene abeparvovec.

\section{NUSINERSEN RESTRICTION SCORES AND DRUG UTILIZATION}

We aggregated restriction scores for each state based on our coverage guidelines and gave each state a score of 1 to 4 . A score of 1 suggested that a state had relatively less restrictive coverage guidelines, whereas a score of 4 suggested that a state had relatively more restrictive coverage guidelines (Table 4). We treated each coverage restriction equally in our composite measure, since we determined that none of the 4 coverage domains warranted a significantly higher weighting.

We then examined if coverage restrictions were associated with other characteristics of the Medicaid program. We did not find any obvious associations with coverage policies for genetic therapies. For example, there were no perceived discernible patterns across state restrictive scores and state Medicaid program characteristics, such as whether a state expanded Medicaid or average Medicaid spending per child.

Next, we examined whether coverage policies were associated with utilization rates for nusinersen. Our results suggested a correlation such that states with higher restriction scores had lower nusinersen utilization rates per 10,000 Medicaid FFS births. States with the most restrictive scores had an average of 51.9 nusinersen prescriptions per 10,000 Medicaid FFS births compared with states with the least restrictive scores, which had 92.9 nusinersen prescriptions per 10,000 Medicaid FFS births (Table 4).

\section{Discussion}

Medicaid coverage policies for nusinersen and onasemnogene abeparvovec varied across states. This variation raises equity concerns regarding patient access to these drugs. This is particularly worrisome given that Medicaid beneficiaries tend to be from disadvantaged populations already facing health care access concerns..$^{17}$ Evidence suggesting access issues was possibly identified in our analysis of restriction scores and nusinersen utilization, where we found a negative correlation between utilization rates for nusinersen and increased coverage restrictions. However, our evidence was not tested for a causal relationship, nor do we know the level of unmet need for either drug. 
The use of detailed coverage policies by state Medicaid programs could be a response to the economics. State Medicaid programs are facing increased drug costs during a time with limited budgets, and a few very high-priced drugs can dramatically influence the state's ability to control drug spending. Genetic therapies can offer tremendous therapeutic value, but it comes with high price tags. Although genetic therapies typically target small populations, collectively they can have significant budget impacts. For Medicaid programs, providers, and patients, it is important for the Medicaid programs to establish coverage policies before the anticipated increase in the number of genetic therapies on the market. Unlike other payers who can pass off some of the higher prices via higher premiums or greater cost sharing, state Medicaid programs must rely on coverage policies to mitigate the budget impact.

\section{POLICY STRATEGIES}

Four policies that state Medicaid programs could use to address ultra-expensive drugs, such as genetic therapies, in addition to the coverage restrictions already discussed are as follows: preferred drug lists, joint purchase agreements, multistate pooled negotiations for supplemental rebates, and a pooled subscription, commonly referred to as the "Netflix" model. ${ }^{18,19}$

A 2012 study using Michigan's Medicaid experience with the first 3 of these strategies demonstrated that the preferred drug list (PDL) generated the greatest cost savings. ${ }^{19}$ However, the PDL strategy generated its savings primarily by switching from expensive drugs to less expensive drugs on a drug list. The use of a PDL strategy may not yield significant savings for state Medicaid programs in the case of genetic therapies because there tends to be limited pharmacotherapy options for the underlying condition. Without competition, either from alternative branded drugs or from generics, the ability for a state to extract rebates, vis-à-vis savings, from manufacturers based solely on placement on a PDL is limited.

A more promising cost containment strategy for genetic therapies and Medicaid programs could be a joint purchase agreement, which occurs when 2 states join together to purchase a drug, thereby (and ideally) increasing the buying power of the states to achieve lower prices. Michigan Medicaid entered into a joint purchase agreement with the state of Vermont in 2003. This agreement resulted in lower brand-name drug prices, although the magnitude of savings was small.

A more robust variation of a joint purchase agreement is a multistate pooled negotiation. As the name implies, this type of agreement includes multiple states, which further increases the monopsony of the buyers. Michigan's experience suggests that multistate negotiation generated significant savings by negotiating lower unit prices for branded drugs. To implement an effective multistate pooled negotiation cost containment strategy, states should agree on a uniform set of coverage policies for a specific drug.

By agreeing to a uniform coverage policy, the states increase the importance of each coverage domain, which can be leveraged with the supplemental rebate negotiations with drug companies. For example, if states agree on a specific SMA drug coverage policy around a patient's ventilator status, they could have better bargaining power, and better bargaining power could yield additional rebates from the drug manufacturer.

Drug companies would want a less restrictive policy to ensure that more infants have access to the SMA drug. If all states agree on a less restrictive policy, then they could extract a larger rebate from drug companies for adopting this policy. This is because, in an all-or-none negotiation, a monopsonist (ie, states collectively purchase the drug) is in a better position to achieve lower prices than if the states acted individually. ${ }^{20}$

In joint purchase and multistate arrangements, there are additional advantages to a more uniformed coverage policy across state Medicaid programs. These types of arrangements reduce the potential inequity for Medicaid patients based on geography and could minimize the incentive for people to move to a different state to seek health care. Another advantage is the reduced administrative burden for the state Medicaid program and the drug company. Currently, states are using resources to develop their own coverage policies for genetic therapies. This requires an extensive review of evidence, which is constantly evolving for genetic therapies. Also, drug companies have administrative expenses associated with coordinating with each individual state for access to their drugs. That said, it is worth noting that many states are moving toward Medicaid pharmacy benefit standardization within each state by requiring Medicaid MCOs to follow the PDL of state FFS Medicaid PDL. ${ }^{8}$

Another state drug purchase arrangement that could help Medicaid programs address the high cost of genetic therapies is a "Netflix" model..$^{21}$ This model is subscription based in that the purchaser (Medicaid program) negotiates with the supplier (drug manufacturer) for unfettered access to a drug using a monthly subscription. This type of model appeals to manufacturers, since it produces a predictable and sustained revenue stream for manufacturers. This 
model has been successfully implemented by the state of Louisiana for the high-cost specialty drugs needed for hepatitis C treatment. ${ }^{22}$

It has also been proposed to combine a multistate purchase agreement with a subscription arrangement for genetic therapies. ${ }^{23}$ This approach could provide additional leverage for the buyers in the negotiation of prices with increased monopsony; however, it is contingent on state Medicaid programs agreeing to uniform coverage guidelines.

\section{LIMITATIONS}

This study has some limitations to consider. First, our study focused on nusinersen and onasemnogene abeparvovec coverage guidelines that were published on state websites. States may have guidelines that are not available on their websites. However, it is worth noting that websites are perhaps the most accessible form of information for Medicaid enrollees and physicians. Second, our estimates of drug utilization were limited to nusinersen due to data availability, since onasemnogene abeparvovec was only approved in May 2019. Third, our restriction scores were unvalidated and assumed that each component should be equally weighted. Our estimates of Medicaid FFS births were based on Medicaid FFS total enrollment proportions, which may not be similar for newborns and may exclude those born in managed care programs funded by the Medicaid program.

\section{Conclusions}

Genetic therapies offer innovative treatments for many debilitating diseases but come with high prices. Medicaid programs cannot use formularies; they must cover all drugs and cannot impose any meaningful cost sharing. Because of this, some states have responded to the high prices by providing detailed coverage guidelines for nusinersen and onasemnogene abeparvovec. There is significant variation in coverage policies across states, raising access concerns. States with more restrictive coverage policies had lower rates of nusinersen. State policymakers should consider adopting uniform coverage policies to facilitate multistate negotiations, reduce access inequity due to geography, and reduce administrative burden. Uniform coverage models could enhance states negotiating power, and this could be translated into increased access through a Netflix subscription type model.

\section{DISCLOSURES}

This study was funded by Arnold Ventures. The authors have no conflicts of interest to disclose.

\section{REFERENCES}

1. Brzustowicz L, Lehner T, Castilla L, et al. Genetic mapping of chronic childhood-onset spinal muscular atrophy to chromosome Sq 11.2-13.3. Nature. 1990;334(6266):540-41. doi:10.1038/344540a0

2. National Human Genome Research Institute. About spinal muscular atrophy. February 19, 2012. Accessed March 15, 2021. https://www. genome.gov/Genetic-Disorders/ Spinal-Muscular-Atrophy

3. Ramdas S, Servais L. New treatments in spinal muscular atrophy: an overview of currently available data. Expert Opin Pharmacother. 2020;21(3):307-15. doi:10.108 0/14656566.2019.1704732

4. Dangouloff T, Servais L. Clinical evidence supporting early treatment of patients with spinal muscular atrophy: current perspectives. Ther Clin Risk Manag. 2019;15:1153-61. doi:10.2147/TCRM. $\underline{\mathrm{S} 172291}$
5. Thomas K. This new treatment could save the lives of babies. But it costs \$2.1. New York Times. May 24, 2019. Accessed June 29, 2020. https://www.nytimes. com/2019/05/24/health/zolgensmagene-therapy-drug.html

6. Stein R. At $\$ 2.1$ million, new genetic therapy is the most expensive drug ever. NPR. May 24, 2019. Accessed June 29, 2020. https://www.npr.org/sections/ health-shots/2019/05/24/725404168/at2-125-million-new-gene-therapy-is-themost-expensive-drug-ever\#: : :text=At\%20 \%242.1\%20Million\%2C\%20New\%20 Gene\%20Therapy\%20Is\%20The\%20 Most\%20Expensive\%20Drug\%20Ever,Listen\%C2\%B7\%204\%3A19\&text=via\%20 Getty\%20Images-,Zolgensma\%2C\%20 a\%20new\%20drug\%20approved\%20 by\%20the\%20FDA\%20Friday\%2C\%20 costs,owned\%20by\%20pharmaceutical \%20giant\%20Novartis.

7. Kaiser Family Foundation. Percent of births financed by Medicaid. Accessed July 30, 2020. https://www.kff.org/ medicaid/state-indicator/birthsfinanced-by-medicaid/?currentTimefram $\underline{\mathrm{e}=0 \& \text { sortModel=\%7B\%22colId\%22:\%22Loc }}$ ation\%22,\%22sort\%22:\%22asc\%22\%7D

8. Dolan R, Tian M. Management and delivery of the medicaid pharmacy benefit. Kaiser Family Foundation. December 6, 2019. Accessed August 11, 2021. https:// www.kff.org/medicaid/issue-brief/ management-and-delivery-of-the-medicaid-pharmacy-benefit/

9. Data.Medicaid.gov. Open Data. Database. Accessed July 30, 2020. https:// data.medicaid.gov/

10. Centers for Disease Control and Prevention. National Vital Statistics System. Birth data. July 9, 2020. Accessed July 30, 2020. https://www.cdc.gov/nchs/ nvss/births.htm

11. March of Dimes. PeriStats. Medicaid coverage of births: United States, 2018. Accessed July 30, 2020. https:// www.marchofdimes.org/Peristats/ ViewSubtopic.aspx?reg=99\&top=11\&stop=1 $\underline{54 \& l e v=1 \& \text { slev }=1 \& \text { obj }=18}$ 
12. Kaiser Family Foundation. State health facts. Total Medicaid MCO enrollment. August 7, 2019. Accessed July 30, 2020. https:// www.kff.org/other/state-indicator/ total-medicaid-mco-enrollment/

13. US Food and Drug Administration. Zolgensma. March 16, 2021. Updated October 26, 2021. Accessed May 27, 2021. https://www.fda.gov/ vaccines-blood-biologics/zolgensma

14. Kaiser Family Foundation. State health facts. Status of state action on the Medicaid expansion decision. August 17, 2020. Accessed September 24, 2020. https://www.kff. org/health-reform/state-indicator/ state-activity-around-expanding-medicaid-under-the-affordable-care-act/

15. Medicaid.gov. Medicaid per capita expenditures. Accessed April 19, 2021. https://www.medicaid.gov/ state-overviews/scorecard/how-muchstates-spend-per-medicaid-enrollee/ index.html
16. Neil EE, Bisaccia EK. Nusinersen: a novel antisense oligonucleotide for the treatment of spinal muscular atrophy. J Pediatr Pharmacol Ther. 2019;24(3):194203. doi:10.5863/1551-6776-24.3.194

17. Allen EM, Call KT, Beebe TJ, McAlpine DD, Johnson PJ. Barriers to care and healthcare utilization among the publicly insured. Med Care. 2017;55(3):207-14. doi:10.1097/MLR.0000000000000644

18. Silow-Carroll S, Alteras T. Stretching state health care dollars: pooled and evidence-based pharmaceutical purchasing. The Commonwealth Fund. October 1, 2004. Accessed November 23, 2021. https://www.semanticscholar.org/ paper/Stretching-State-Health-CareDollars\%3A-Pooled-and-Alteras-SilowCarroll/4b55e544924f200b1188bc0e1b18e 5bfab232cb1

19. Kibicho J, Pinkerton SD. Multiple drug cost containment policies in Michigan's Medicaid program saved money overall, although some increased costs. Health Aff (Millwood). 2012;31(4):816-26. doi:10.1377/ hlthaff.2011.0246
20. Herndon JB. Health insurer monopsony power: the all-or-none model. J Health Econ. 2002;21(2):197-206. doi:10.1016/S0167-6296(01)00117-5

21. Trusheim MR, Bach PB. Next steps for Netflix: can 'all you can treat' contracts work beyond hepatitis C? Health Affairs Blog. September 25, 2019. Accessed September 24, 2020. http:// www.healthaffairs.org/do/10.1377/ hblog20190924.559225/full/

22. Trusheim MR, Cassidy WM, Bach PB. Alternative state-level financing for hepatitis C treatment-the "Netflix model." JAMA. 2018;320(19):1977-78. doi:10.1001/ jama.2018.15782

23. Ballreich J, Ezebilo I, Sharfstein J. Affording genetic therapies in the Medicaid program. JAMA Pediatr. 2020;174(6):523-24. doi:10.1001/ jamapediatrics.2020.0168 